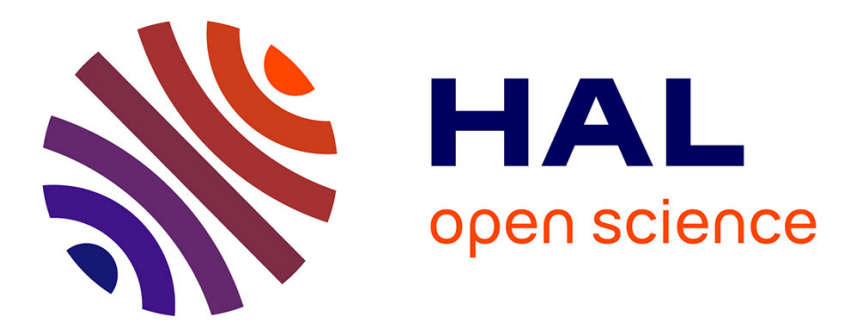

\title{
The Complex Role of Aluminium Contamination in Nickel-Rich Layered Oxide Cathodes for Lithium-Ion Batteries
}

Juhan Lee, Houari Amari, Mounib Bahri, Zonghao Shen, Chao Xu, Zachary Ruff, Clare P. Grey, Ovidiu Ersen, Ainara Aguadero, Nigel D. Browning, et al.

\section{To cite this version:}

Juhan Lee, Houari Amari, Mounib Bahri, Zonghao Shen, Chao Xu, et al.. The Complex Role of Aluminium Contamination in Nickel-Rich Layered Oxide Cathodes for Lithium-Ion Batteries. Batteries \& Supercaps, 2021, 4, pp.1-9. 10.1002/batt.202100110 . hal-03450338

\section{HAL Id: hal-03450338 https://hal.science/hal-03450338}

Submitted on 25 Nov 2021

HAL is a multi-disciplinary open access archive for the deposit and dissemination of scientific research documents, whether they are published or not. The documents may come from teaching and research institutions in France or abroad, or from public or private research centers.
L'archive ouverte pluridisciplinaire HAL, est destinée au dépôt et à la diffusion de documents scientifiques de niveau recherche, publiés ou non, émanant des établissements d'enseignement et de recherche français ou étrangers, des laboratoires publics ou privés. 


\title{
The Complex Role of Aluminium Contamination in Nickel- Rich Layered Oxide Cathodes for Lithium-Ion Batteries
}

\author{
Juhan Lee ${ }^{+[a, f]}$ Houari Amari ${ }^{+}{ }^{[a, f]}$ Mounib Bahri, ${ }^{[a, d]}$ Zonghao Shen ${ }^{[f, g]}$ Chao Xu, ${ }^{[e, f]}$ \\ Zachary Ruff, ${ }^{[e, f]}$ Clare P. Grey, ${ }^{[e, ~ f]}$ Ovidiu Ersen, ${ }^{[d]}$ Ainara Aguadero, ${ }^{[f, g]}$ \\ Nigel D. Browning, ${ }^{[a, b, c, f]}$ and B. Layla Mehdi*[a, f]
}

\begin{abstract}
A major challenge for lithium-ion batteries based on nickel-rich layered oxide cathodes is capacity fading. While chemomechanical degradation and/or structural transformation are widely considered responsible for degradation, a comprehensive understanding of this process is still not complete. For the stable performance of these cathode materials, aluminium (Al) plays a crucial role, not only as a current collector but also as substitutional element for the transition metals in the cathodes and a protective oxide coating (as $\mathrm{Al}_{2} \mathrm{O}_{3}$ ). However, excess $\mathrm{Al}$ can be detrimental due to both its redox inactive nature in the cathode and the insulating nature of $\mathrm{Al}_{2} \mathrm{O}_{3}$. In this work, we report an analysis of the $\mathrm{Al}$ content in two different types of nickel-rich manganese cobalt oxide cathode materials after battery cycling. Our results indicate a significant thickening of Al-containing phases on the surface of the NMC811 electrode. Similar results are observed from commercial batteries (a mixture of $\mathrm{NMC} 532$ and $\mathrm{LiMn}_{2} \mathrm{O}_{4}$ ) that were analysed before use and at the end of life, where Al-containing phases were found to increase significantly at surfaces and grain boundaries. Considering the detrimental effects of the excess $\mathrm{Al}$ in the nickel-rich cathodes, our observation of increased Al content via battery cycling is believed to bring a new perspective to the ongoing discussions regarding the capacity fading phenomenon of nickel-rich layered oxide materials as part of their complex degradation mechanisms.
\end{abstract}

The global demand for electrochemical energy storage systems has led to an increase in research into the development of advanced lithium-ion batteries (LIB). ${ }^{[1-6]}$ From fulfilling individual needs for the small-scale storage of electricity in household gadgets, to providing larger-scale storage capacities in electric vehicles, LIBs have now become an intrinsic part of human activities, that promises to increase significantly in the future as we all strive for cleaner energy with a reduced environmental impact. ${ }^{[6,7]}$ To increase the applications of LIBs and facilitate their incorporation into more aspects of modern society, current research goals aim to address current limitations by making LIBs cheaper, safer, more durable, and higher-performing both per unit mass and per unit volume. ${ }^{[2,8]}$ Developments of these technologies must also bear in mind the need for an environmentally friendly circular economy, providing routes to battery recycling.

One of the materials that is currently being investigated to overcome the limited charge storage capacity $(<200 \mathrm{mAh} / \mathrm{g})$ of conventional lithium-ion battery materials (e.g. $\mathrm{LiMn}_{2} \mathrm{O}_{4}$, LiFe$\mathrm{PO}_{4}$, and $\mathrm{LiCoO}_{2}$ cathodes) ${ }_{1}^{[9,10]}$ is nickel-rich layered materials with high-energy densities such as $\mathrm{LiNi}_{x} \mathrm{Co}_{y} \mathrm{Al}_{z} \mathrm{O}_{2}$ (NCA) and $\mathrm{LiNi}_{x} \mathrm{Mn}_{y} \mathrm{Co}_{z} \mathrm{O}_{2}$ (NMC). ${ }^{[5,8]}$ Despite the high intrinsic charge storage capacity in NMC ( $>220 \mathrm{mAh} / \mathrm{g})$ which can contribute to energy density approaching $800 \mathrm{Wh} / \mathrm{kg}$ in battery cells, a major challenge of nickel-rich materials is performance degradation, particularly in terms of capacity fading. ${ }^{[9,11,12]}$ The primary origin of this fading with the number of charge- [a] Dr. J. Lee, ${ }^{+}$Dr. H. Amari, ${ }^{+}$Dr. M. Bahri, Prof. N. D. Browning, Dr. B. L. Mehdi Department of Mechanical,

Materials and Aerospace Engineering

University of Liverpool

Liverpool, L69 3GH, UK

E-mail: b.l.mehdi@liverpool.ac.uk

[b] Prof. N. D. Browning

Pacific Northwest National Laboratory

Richland, WA 99352, USA

[c] Prof. N. D. Browning

Sivananthan Laboratories

590 Territorial Drive, Bolingbrook, IL 60440, USA

[d] Dr. M. Bahri, Dr. O. Ersen

Institut de Physique et Chimie des Matériaux de Strasbourg

(IPCMS)-UMR 7504 CNRS

Université de Strasbourg

67034 Strasbourg Cedex 2, France [e] Dr. C. Xu, Dr. Z. Ruff, Prof. C. P. Grey

Department of Chemistry

University of Cambridge

Cambridge CB2 1EW, UK

[f] Dr. J. Lee, ${ }^{+}$Dr. H. Amari, ${ }^{+}$Dr. Z. Shen, Dr. C. Xu, Dr. Z. Ruff, Prof. C. P. Grey, Dr. A. Aguadero, Prof. N. D. Browning, Dr. B. L. Mehdi

The Faraday Institution, Quad One

Harwell Science and Innovation Campus

Didcot OX110RA, UK

[g] Dr. Z. Shen, Dr. A. Aguadero

Department of Materials

Imperial College London

SW7 2AZ, London, UK

$\left.{ }^{[+}\right]$These authors contributed equally to this work.

Supporting information for this article is available on the WWW under https://doi.org/10.1002/batt.202100110

○ ( 2021 The Authors. Batteries \& Supercaps published by Wiley-VCH GmbH. This is an open access article under the terms of the Creative Commons Attribution License, which permits use, distribution and reproduction in any medium, provided the original work is properly cited. 
discharge cycles, has been explained by their vulnerable nature to chemo-mechanical degradation and detrimental structural transformation compared to their low nickel-containing alternatives. $^{[12-15]}$

Analysis of NMC under a wide variety of cycling conditions has revealed an extensive understanding of potential degradation effects. These include oxygen depletion, phase transformations to the spinel and rock-salt structures, transition metal dissolution, and side reactions at the cathode/electrolyte interface. ${ }^{[9,12,16,17]}$ While comprehensive mechanisms for how these complex parameters mutually interact and govern overall performance degradation, surface coatings of nickel-rich layered particles such $\mathrm{MgO}$ and $\mathrm{Al}_{2} \mathrm{O}_{3}$ have already been applied as effective solutions that enhance cyclic performance. ${ }^{[17-19]}$ The improved capacity retention created by these coatings is widely believed to be enabled by suppressing both the undesired surface reactions and the structural and chemical transitions within the cathode material. ${ }^{[17,19-21]}$ Nonetheless, there are as yet few reports of the underlying mechanisms through which these coating layers interact with the active cathode particles. ${ }^{[17,20]}$

Along with forming an oxide protection layer $\left(\mathrm{Al}_{2} \mathrm{O}_{3}\right)$ and substitution of electrochemically-active elements (e.g. NCA), aluminium (Al) chemistry in LIBs has also played a crucial role in current collectors within the cathode compartment. When being applied as a thin foil as current collectors for cathodes, metal Al alone is considered to be vulnerable to corrosions such as a hole or pitting formation. ${ }^{[22-25]}$ Fortunately, the surface of the initial metal $\mathrm{Al}$ can be protected by an $\mathrm{Al}_{2} \mathrm{O}_{3}$ passivation layer which can be naturally formed depending on the type of the electrolyte and its impurity content (with impurities such as $\mathrm{H}_{2} \mathrm{O}$ and $\mathrm{HF}$ being present). ${ }^{[24-29]}$ Recent studies, however, show that even with an $\mathrm{Al}_{2} \mathrm{O}_{3}$ layer, $\mathrm{Al}$ current collectors can be still exposed to chemical and anodic dissolution. ${ }^{[25,30]}$ With the presence of $\mathrm{HF}$, the $\mathrm{Al}_{2} \mathrm{O}_{3}$ layer can be converted to more stable $\mathrm{AlF}_{3}$, meaning that $\mathrm{LiPF}_{6}$-based electrolytes may have a performance advantage as they generate $\mathrm{HF}$ through a decomposition reaction with water. ${ }^{[25,31]}$ However, Zhang et al. reported that the $\mathrm{Al}$ current collector in a $\mathrm{LiPF}_{6}$-containing electrolyte is still susceptible to corrosion. ${ }^{[23]}$

To understand the role that Al may play in controlling the capacity fading mechanism of nickel-rich layered oxide cathodes in LIBs, here we report the age-driven aluminium contamination process on NMC-type nickel-rich layered oxides by investigating the two different commercially available battery cathodes. Through atomic scale scanning transmission electron microscopy (STEM) observations coupled with time-offlight secondary ion mass spectrometry (ToF-SIMS) we find that the $\mathrm{Al}$ in the system migrates during cycling to interfaces and defects, in some cases leading to nanoscale intergranular films being formed. As such films are known to have a deleterious effect on battery performance, here we discuss the correlation between the observed aluminium contamination to the surface layers on the nickel rich cathodes and the evolution of the properties of the system with cycling history.

While the structure of the commercially available LIBs varies from a single-stack coin cell to multi-stack pouch or cylindrical cells, the layout inside the batteries is almost identical; consisting of a cathode (or positive electrode), an anode (or negative electrode), a porous separator, and current collectors (schematically described in Figure 1A). In the case of commercial LIBs with NMC cathodes, graphite is generally the anode material, with $\mathrm{Al}$ and copper $(\mathrm{Cu})$ current collectors in the cathode and anode, respectively. The Targray NMC811 cathode particles used in this work have a typical morphology of spherical secondary particles consisting of primary particles ${ }^{[12,15,32]}$ as presented by scanning electron microscopy (SEM) (see also Supporting Information, Figure S1); the primary particles within a size of ca. $0.1-0.2 \mu \mathrm{m}$ are densely packed, forming spherical secondary particles of a size of about 4$20 \mu \mathrm{m}$ (Figure S1A-B).

The average capacity retention performance of the NMC811 cathodes from two LIB coin cells is shown in Figure 1B. To investigate the origin of the capacity fade in these cathode materials, the samples were collected after 1 and 300 battery ageing cycles at $4.2 \mathrm{~V}$ and subsequently reassembled in lithium half-cells and delithiated to the same charged state $(4.3 \mathrm{~V}$ vs. Li). Then, we examined several secondary particles from the sample after 300 cycles by continuous cross-sectioning via a focused-ion beam, FIB. As demonstrated by one of these examples (see also Supporting Information, Figure S1C), we have found no visible sign of crack formation in the investigated samples. These results are consistent with our previous study by in situ XRD and imply that chemo-mechanical degradation is not a governing factor for the capacity fading in these materials. ${ }^{[33]} A$ rather convincing explanation for at least one source of capacity fade (of the cathode) is the surface reconstruction on the edge of the NMC811 particle from the initial layered rhombohedral $(R \overline{3} m$, Figure $1 C)$ to face-centred cubic $(F m \overline{3} m$, ) Figure1D structure. The formation of a surface rocksalt structure orthogonal to Li diffusion channels can pin the lattice planes of the $R \overline{3} m$ layered structure and lead to a limited maximum state-of-charge for lithium deintercalation. ${ }^{[33]}$

To investigate further avenues for performance degradation in nickel-rich layered oxides materials, three NMC811 electrodes at different ageing conditions were examined for ToF-SIMS analysis: the pristine Targray electrode, and the Targray cathodes after 1 and 300 cycles at $4.2 \mathrm{~V}$ in a full-cell configuration. In a negative acquisition mode, $\mathrm{Al}$ was found on a large area of the surface $(250 \mu \mathrm{m} \times 250 \mu \mathrm{m})$ of all samples as evidenced by $\mathrm{Al}^{+}, \mathrm{AlO}^{-}, \mathrm{AlO}_{2}^{-}$, and $\mathrm{AlF}_{4}^{-}$fragments (Supporting Information, Figure $\mathrm{S} 2-3$ ). These fragments can all be identified as components that could originate from the $\mathrm{Al}_{2} \mathrm{O}_{3} \mathrm{NMC}$ coatings, these coatings reacting with $\mathrm{HF}$ to give $\mathrm{AlF}_{3}$, or the $\mathrm{Al}$ current collector and its $\mathrm{Al}_{2} \mathrm{O}_{3}$ natural oxide. ${ }^{[21,24-26,34-36]}$ The formation of $\mathrm{AlF}_{3}$ or $\mathrm{Al}_{2} \mathrm{O}_{3}$ may have also been enabled by additional sources of $\mathrm{Al}$ in the electrolyte (as a poison or an additive). However, the concentration of Al in the pristine electrolyte was below the detection limit of our inductively coupled plasma atomic emission spectroscopy (ICP-OES) measurement $(<3.5 \mu \mathrm{g} / \mathrm{L}$ or $<175 \mathrm{ng}$ in the $50 \mu$ l of electrolyte used per cell); details in Supporting Information Table S1. Taking the upper-bound of the potential Al contamination in the pristine electrolyte, this would correspond to $<3.0 \times 10^{-5}$ ratio of Al to 
A +

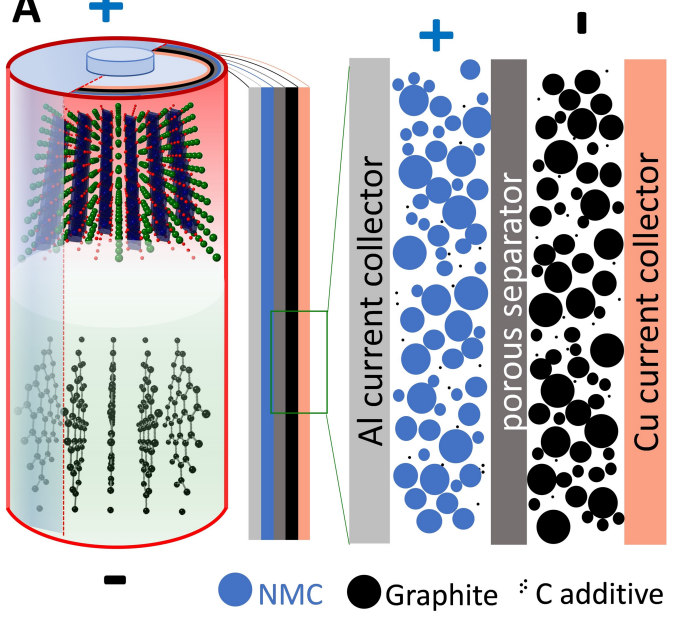

B

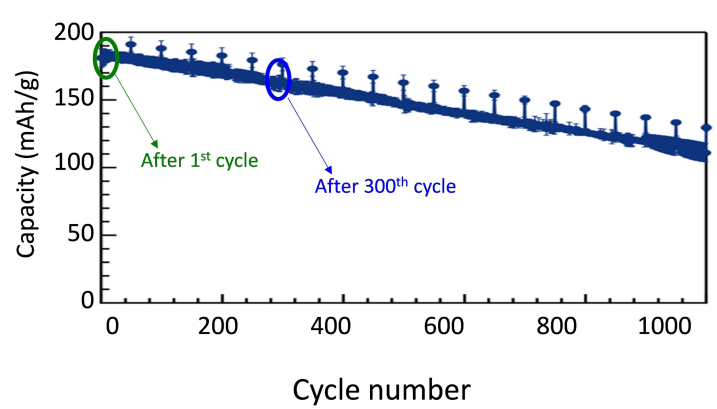

C

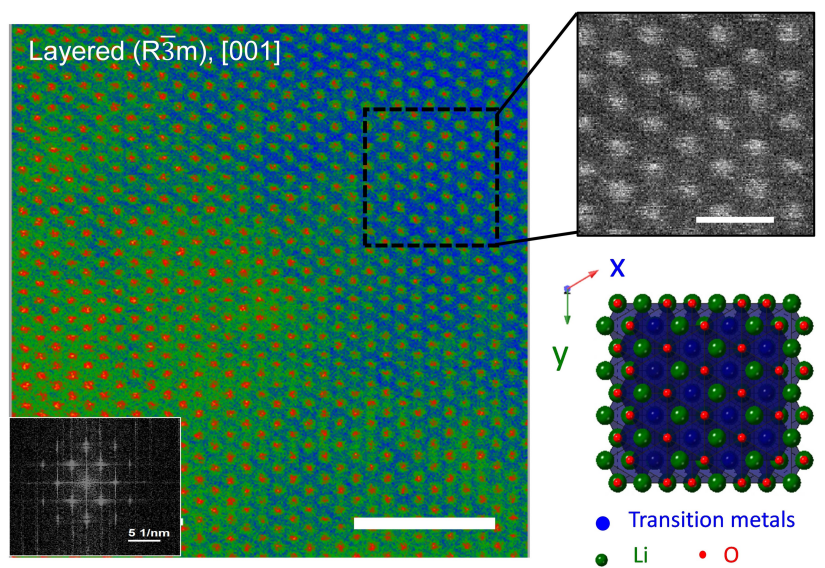

D

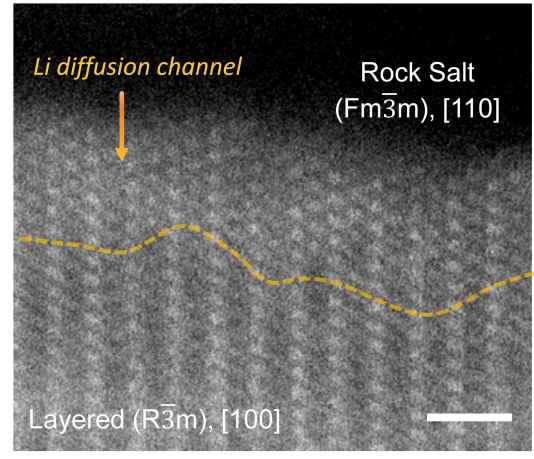

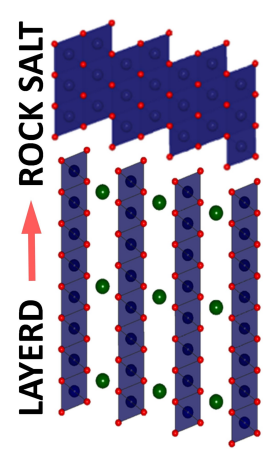

Figure 1. A) Schematic illustration of a lithium-ion battery cell. For simplicity, the binding material is not illustrated. However, in our study, we applied PVDF binder for NMC811 cathodes. B) Capacity fading of NMC811 Targray cathodes. C-D) ADF-STEM images of the NMC811 Targray particle. C) Layered rhombohedral structure of the pristine electrode in [001] zone axis. The scale in the main image is $2 \mathrm{~nm}$, and $0.5 \mathrm{~nm}$ in the inset on the right. D) Rock salt is formed orthogonal to the lithium diffusion channels of the layered structure.

transition metals in the NMC811 cathode and would not likely be challenging to quantify on a bulk scale by the STEM-EDX measurements discussed later. A more significant source of $\mathrm{Al}$ is corrosion from the Al-current collector (at the cathode). ICPOES measurements have shown Al $\mu$-level deposits on the anode after cycling, indicating that there is significant Al dissolution, migration and deposition in these cells (Supporting Information, Figure S6). We also note that significant deposits of nickel, manganese and cobalt also were measured at the anode in agreement with other studies on NMC cathodes. ${ }^{[37,38]}$

The normalised ToF-SIMS depth profiles no deeper than $\sim 500 \mathrm{~nm}$ from the surface obtained via $\mathrm{Cs}^{+}$sputtering (Figure $2 \mathrm{~A}$, point-to-point normalised to the total counts) show a general tendency in all samples that the $\mathrm{AlO}^{-}$signals increase at the beginning of the sputtering and start decreasing after reaching the peak values. The same trend was observed for the $\mathrm{AlF}_{4}^{-}$signal from the sample after 300 cycles while the monotonous weakening of the $\mathrm{AlF}_{4}{ }^{-}$signal can be perceived for the pristine electrode and the sample after the $1^{\text {st }}$ cycle. These tendencies indicate the presence of an $\mathrm{Al}$ and $\mathrm{F}$ containing layer on the surface of the secondary NMC particles and $\mathrm{Al}$ and $\mathrm{O}$ containing layer underneath. These results are consistent with the related Li-ion battery studies that $\mathrm{AlF}_{3}$ layers can be formed on the $\mathrm{Al}_{2} \mathrm{O}_{3}$ layer through a reaction with
HF. ${ }^{[21,25,26]}$ Based on the ToF-SIMS data for the pristine electrode, the possible structure of the NMC primary particle was schematically illustrated in Figure $2 \mathrm{~B}$; the illustration is not precisely scaled with the actual size of the phases, the size of the primary and secondary particles are roughly estimated based on the SEM images (Supporting Information, Figure S1).

As the cycle number increases (Figure 2A), the signal intensities for $\mathrm{AlF}_{4}^{-}$and $\mathrm{AlO}^{-}$gradually enhance, implying that $\mathrm{Al}$ is introduced to the NMC particles from additional Al sources. While the presence of these fragments is consistent with other related studies regarding $\mathrm{Al}_{2} \mathrm{O}_{3}$ and $\mathrm{AlF}_{3}$ passivation layers, ${ }^{[18,21,24-26]}$ the increased Al content in Nickel-rich cathodes after battery ageing processes has not been reported so far. Also, we found that the peak of $\mathrm{AlO}^{-}$signal shifts to higher sputtering cycles at higher battery cycling numbers while no such shift was observed for the $\mathrm{AlF}_{4}^{-}$signal (see also Supporting Information, Figure $\mathrm{S} 2 \mathrm{~B}$ ). The shift of $\mathrm{AlO}^{-}$signal may originate in the thickening of the cathode electrolyte interface (CEI) consisting of species like $\mathrm{LiF}, \mathrm{Li}_{2} \mathrm{CO}_{3}$, and $\mathrm{Li}_{x} \mathrm{PO}_{y} \mathrm{~F}_{z} \cdot{ }^{[39-42]}$ The $\mathrm{CEl}$ layer can be effectively investigated based on $\mathrm{F}$ containing signals such as $\mathrm{Li}_{2} \mathrm{~F}_{3}{ }^{-}$and $\mathrm{LiF}_{2}{ }^{-}$(Figure $2 \mathrm{C}$, see also Supporting Information, Figure S3). ${ }^{[39]}$ The profiles of these signals, however, did exhibit only a fraction of a shift as compared to the $\mathrm{AlO}^{-}$profile. Therefore, the peak shift from 

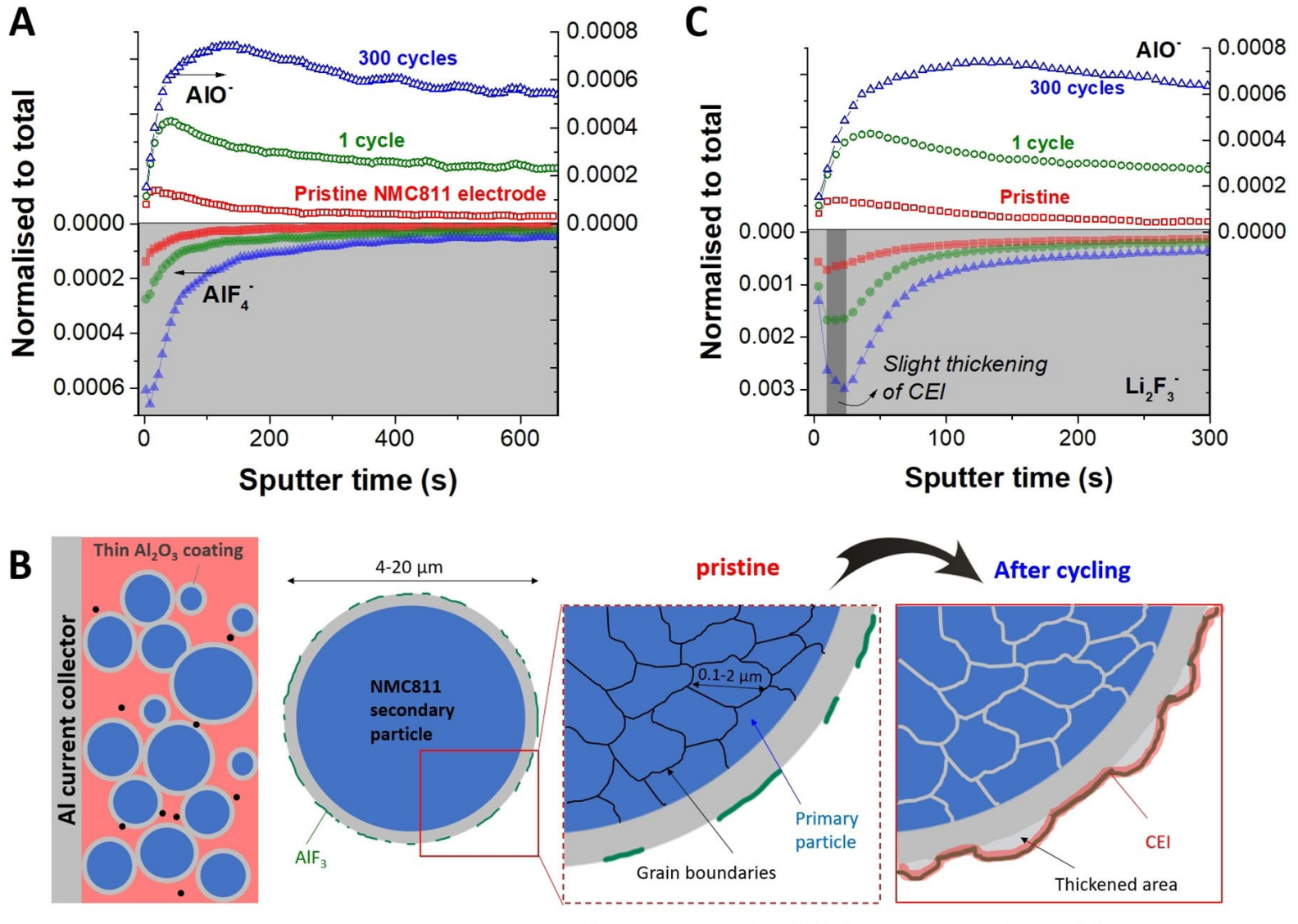

* the thickness of $\mathrm{Al}_{2} \mathrm{O}_{3}$ and $\mathrm{AlF}_{3}$ does not represent the actual size

Figure 2. ToF-SIMS data and schematic illustration of NMC811 Targray electrode. A) Depth profiles for $\mathrm{AlO}^{-}$and $\mathrm{AlF}_{4}^{-}$fragments obtained by Cs ${ }^{+}$sputtering for the pristine NMC electrode and the NMC Targray cathode after 1 and 300 cycles at $4.2 \mathrm{~V}$ in a full cell. The intensity is point-to-point normalised to the total counts. B) Schematic illustration of the cathode compartment in a full cell, a secondary particle with $\mathrm{Al}_{2} \mathrm{O}_{3}$ and $\mathrm{AlF}_{3}$ coating layers, and the detailed illustration for the pristine and the aged sample; from left to right. C) Depth profiles for $\mathrm{AlO}^{-}$and $\mathrm{Li}_{2} \mathrm{~F}_{3}{ }^{-}$fragments.

the $\mathrm{AlO}^{-}$is considered to be caused more likely due to the thickening of the Al-containing layer rather than due to the growth of the CEl layer.

The cathode materials described above have also been analysed by Z-contrast imaging ${ }^{[40]}$ and energy dispersive X-ray spectroscopy $(E D X)^{41}$ in the scanning transmission electron microscope (STEM). The $\sim 1 \mathrm{~nm}$ spatial resolution of the Zcontrast images, which allow variations in mass-thickness to be easily observed, and the EDX spectra, which allow the composition variations to be quantified to $\sim 2-5 \%$ accuracy, permit the locations of the Al phases observed by ToF-SIMS to be identified within the microstructure of the cathode materials. To investigate this spatial distribution, we examined 5 random areas from the various primary particles in the size of $0.1-2.0 \mu \mathrm{m}$ for each sample via STEM-EDX. The elemental signal mapping data (Figure $3 \mathrm{~A}$ ) indicates that particles in all samples (pristine NMC811 powder, electrodes after 1 and 300 cycles) contain $\mathrm{O}, \mathrm{Mn}, \mathrm{Co}$ and $\mathrm{Ni}$, which are core elements of the NMC cathode. Consistent with the ToF-SIMS, there is a trace level of $\mathrm{Al}$ in the pristine electrode, ${ }^{[21]}$ and an increased concentration of Al distributed within and upon the aged cathode materials (Supporting Information, Figure S4).
A further detailed demonstration of the statistical analysis, the elemental composition of $\mathrm{Ni}, \mathrm{Mn}, \mathrm{Co}$, and $\mathrm{Al}$ is shown in Figure $3 \mathrm{~B}$ (see also Supporting Information for the entire elemental composition containing oxygen, Figure S5A). The analysed data shows a relatively homogeneous stoichiometry of $\mathrm{Ni}, \mathrm{Mn}$, and $\mathrm{Co}$ (ca. 8:1:1) for all investigated samples as also evidenced by uniformly distributed mapping signals (see also Supporting Information, Figure S4B). Interestingly, the distribution of the higher $\mathrm{Al}$ content (Figure $3 \mathrm{~B}$, inset) after an increased number of battery cycles suggests that $A l$ is present not only at the outer shell of the secondary particles but also in the primary particles beneath the surface (see also Supporting Information for the detailed evidence of Al, Figure S4C-F).

As shown in Figure 1 and discussed earlier in this paper, the initial layered structure of NMC can be converted into a spinel and/or rock salt-like structure when the NMC cathode undergoes long-term electrochemical cycling. ${ }^{[14,33,44]}$ Interestingly, ${ }^{[33]}$ the samples used in this work did not undergo such major structural transformations; instead, a partial transition from the layered structure to the face-centred cubic structure was observed at the surface layer after 300 cycles at the cell voltage of $4.2 \mathrm{~V}$. This surface-reconstructed area is shown in ADF-STEM images Figure $3 C$ to exist over no more than a few unit cells at 

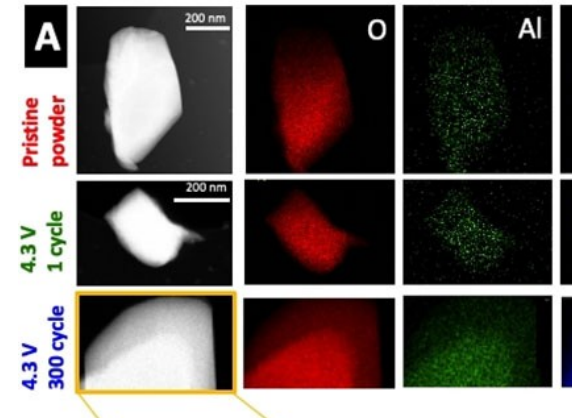

C

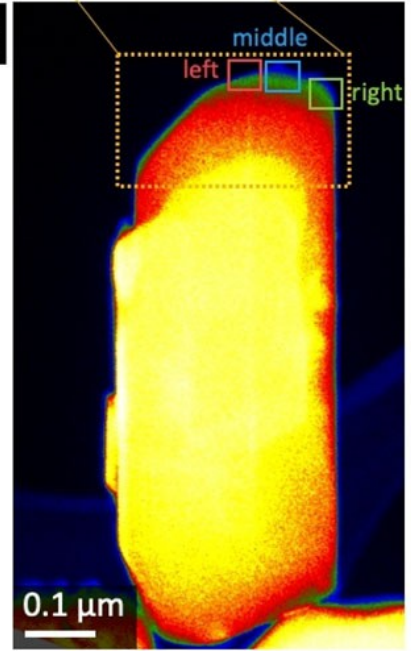

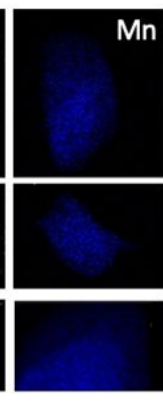

left
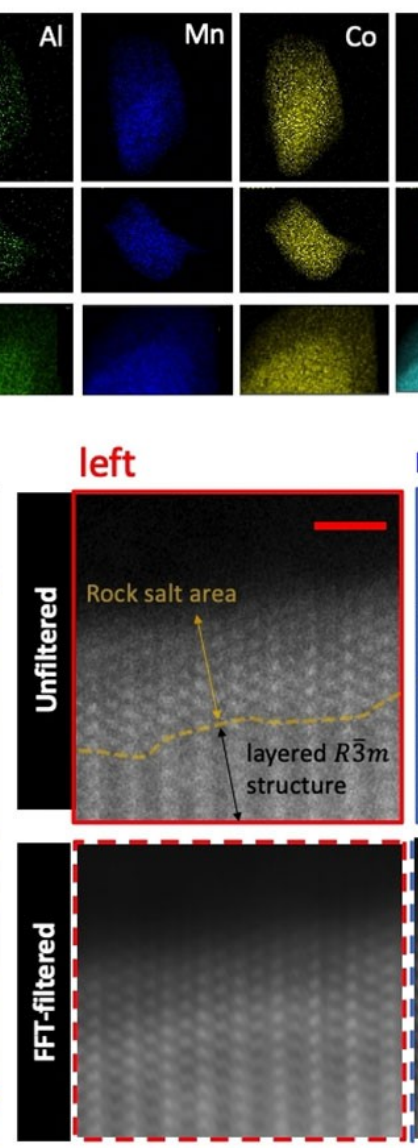
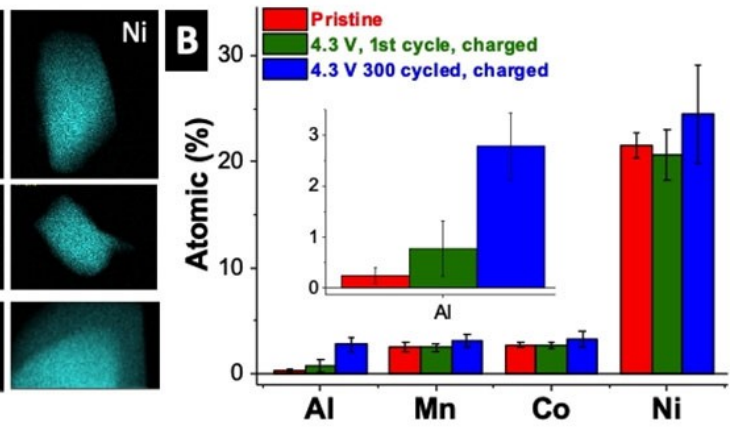

middle

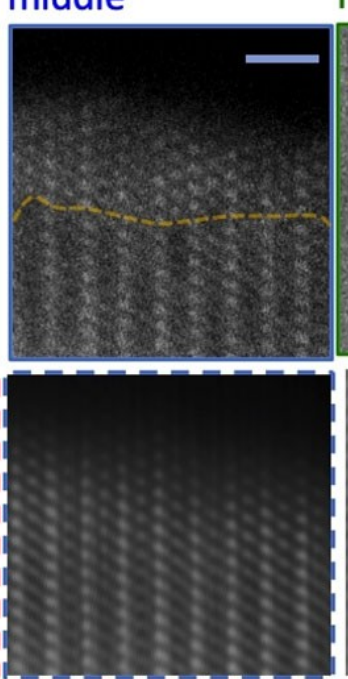

right

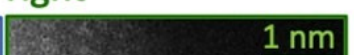

Figure 3. STEM-EDX analysis of the pristine NMC811 Targray powder and NMC811 Targray cathodes after 1 and 300 cycles at $4.2 \mathrm{~V}$ in a full cell. A) Elemental EDX mapping based on signal integral. B) Statistical elemental composition based on EDX analysis. C) ADF-STEM image of the particle after 300 cycles presented in (A) in the bottom row. Insets show ADF-STEM atomic resolution images for the areas labelled as left, middle, and right; the unfiltered images in the top row and FFT-filtered images in the bottom row.

the particle surfaces associated with a surface covering of alumina. Based on the crystal structure and the distribution of Al content (Figure $3 \mathrm{~A}$, see also Supporting Information, Figure $\mathrm{S} 6 \mathrm{~B}$ ), it seems unlikely that the high Al content after cycling is contained only within the rock-salt structure, but rather that the alumina surface layer controls the formation of this surface phase. ${ }^{[45,46]}$ Given the nature of the cathode materials, i.e. polycrystalline, a possible location for the Al-containing phase is along the grain boundaries between the primary particles.

One means to be able to see the Al presence at grain boundaries would be to further cycle the materials and increase the Al content even further. Unfortunately, this was not possible with the raw materials available for the controlled cycling study shown above, end of life came shortly after the current number of cycles. However, we can access the distribution of Al after extended cycling by using the STEM-EDX method to characterise highly aged commercial batteries which consist of similar cathode materials. Figure 4 shows EDX maps obtained from $1^{\text {st }}$ generation Nissan Leaf batteries. The first set of maps is from a pristine battery cathode from a quality control (QC) failed cell, while the second set of maps is obtained from an end-of-life cell that had been driven in a Nissan Leaf for many years. While these battery materials do not have the controlled history of the samples shown in Figure 1-3, all samples were dismantled in glove boxes and used powders from the same source (in this case there are additional variables, as in the first generation of Nissan Leaf batteries used a mixture of LMO and Al doped NMC (532) for its cathode materials). Of key importance in these results is the observation of a more uniform distribution of Al at low-levels in the pristine material, that is transformed into a higher concentration at specific locations in the end-of-life battery. The large deposits of Al-containing phases seem to correspond to "pockets" at major intersections between the grains of the primary cathode particles. However, such large Al agglomerates were not observed in the case of the NMC811 in the initial 300 cycles (probably due to the higher starting Al content in these real-world materials). A likely scenario here is that the amount of $\mathrm{Al}_{2} \mathrm{O}_{3}$ in the grain boundary is not sufficient to be quantified by EDX (anything less than $\sim 2 \%$ will likely be below the noise threshold) for the latter case. Nonetheless, the similarity in the pristine materials and the extension of the same behaviour in both these samples indicates that the mobility of the Alcontaining phases in the cathode is a real effect that must be considered for degradation and given that these are now distinct phases that are present, also for the recycling of LIBs. 
Pristine, Nissan leaf Battery
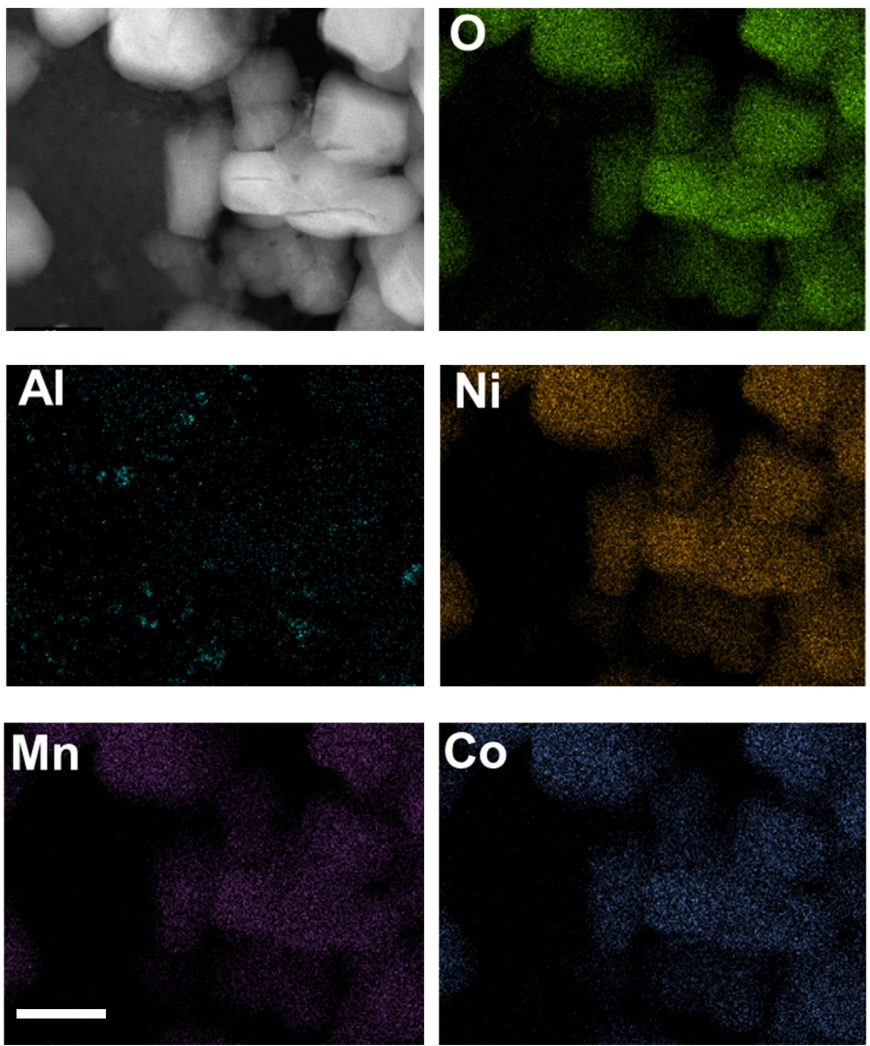
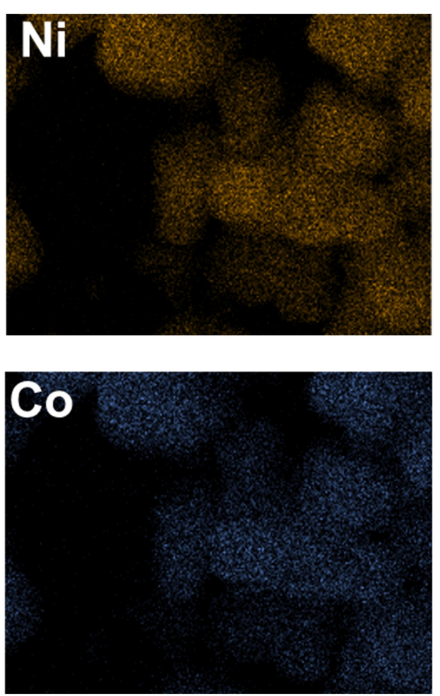
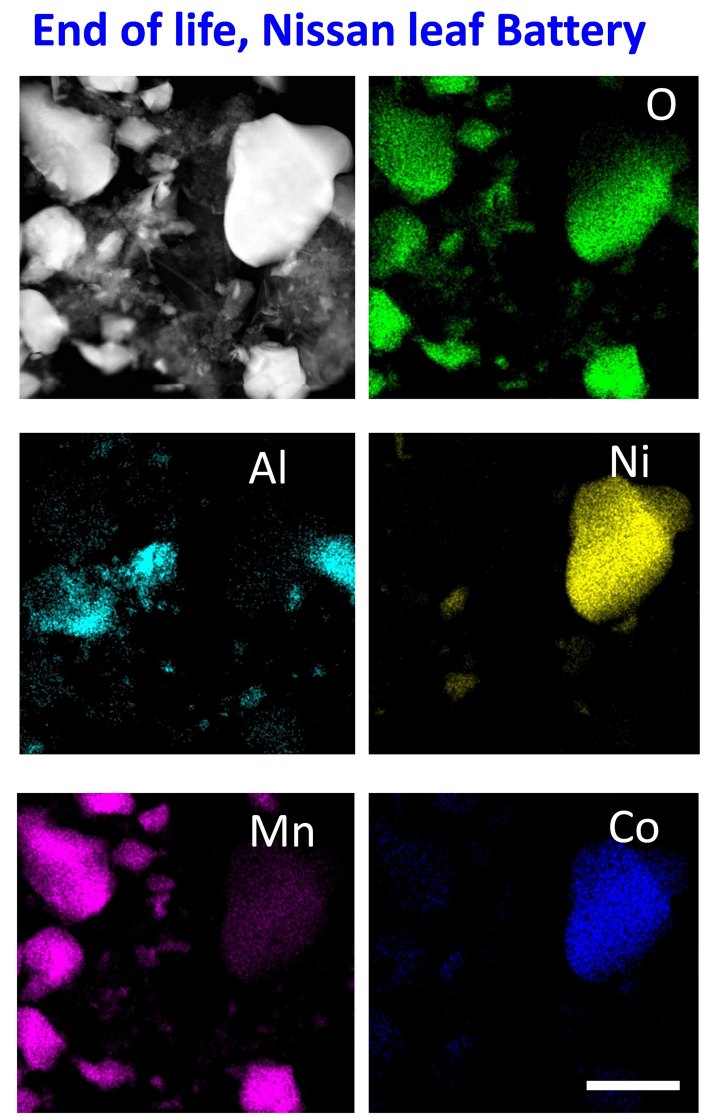

Figure 4. STEM-EDX maps showing the presence and distribution of Al in A) a pristine and B) an end-of-life cathode from a first generation Nissan leaf battery. Over the extended cycling of the battery, Al containing phases appear to increase and form primarily at grain boundary triple pockets. Care was taken to acquire samples away from the Al current collector to avoid contamination artifacts, and all sample preparation took place in a glove box. The formation of large Al phases has an effect on degradation, recycling and second life applications of LIBs. The scale bar is 0.5 and $2.0 \mu \mathrm{m}$ for the pristine and the end of life electrode, respectively.

While the ToF-SIMS and STEM-EDX analysis evidently indicate the increasing $\mathrm{Al}$ content during ageing/degradation, the exact origin of $\mathrm{Al}$ is unclear at this stage. The possible sources of $\mathrm{Al}$ could be $\mathrm{Al}_{2} \mathrm{O}_{3}$ surface layers on the primary cathode particles and the $\mathrm{Al}$ current collector. Based on the previous studies regarding the $\mathrm{Al}$ current collector in $\mathrm{LIBs}^{[23,25,30,24-29]}$ perhaps the most obvious route is the dissolution of the current collector to the electrolyte (see also Supporting Information, Figure S6), but identification of the exact mechanism will be the subject of future work. While the origin of the excess Al may not be easily identifiable, there is no doubt from the different sets of results that it is present upon cycling, and as such we can speculate as to its role in degradation processes. Considering the electrically insulating feature and redox inactive nature of $\mathrm{Al}_{2} \mathrm{O}_{3}$ for the lithium battery operations, the thickness of the protective aluminium oxide layer has been shown to be optimised at a value of $\sim 2 \mathrm{~nm} \cdot{ }^{[47,48]}$ For instance, Zhu et al. systematically investigated the influence of $\mathrm{Al}_{2} \mathrm{O}_{3}$ coating layer on NMC811 via atomic layer deposition and observed a detrimental effect of the coating layer to lithium storage capacity when the thickness exceeds $5 \mathrm{~nm} \cdot{ }^{[48]}$ Hence, only the adequate amount of $\mathrm{Al}$ on the coating layer seems to be beneficial, which can help with the diffusion of $\mathrm{Li}$ into the NMC while at the same time suppressing the formation of a CEl layer, improving cyclability of the material. ${ }^{[4]]}$ In addition, as discussed here, there also appears to be a decrease in the formation of secondary phases during cycling when $\mathrm{Al}$ is present, further decreasing the capacity fading of the system. The presence of the Al-containing phase at grain boundaries may offer another benefit. Intergranular films have for many years been used with polycrystalline ceramic oxides and nitrides to reduce crack propagation and improve overall mechanical properties. ${ }^{[49]}$ The lack of chemo-mechanical deformation in these samples may be an indication of this effect. The grain boundary effect is also supported by the presence of larger Al deposits in the end-of-life commercial battery. It is known that diffusion typically takes place in intergranular films resulting in large deposits at the triple points in the grain boundary networks. ${ }^{[50]}$ The continual supply of Al from other parts of the battery structure may turn the advantageous $\mathrm{Al}_{2} \mathrm{O}_{3}$ interface layer that helps suppress capacity fading at the start of life into a process that accelerates it as the battery continues to age and these phases increase beyond the critical thickness.

To conclude, we have investigated the role of Al contamination on the battery ageing process using ToF-SIMS and STEM-EDX analysis. Pristine NMC 811 samples possessing a sub- 
$\mathrm{nm}$ coating of $\mathrm{Al}_{2} \mathrm{O}_{3}$ are found to be increasingly covered with thicker layers of Al-containing phases as the cycling and ageing process proceeds - evidence suggests the thickening is an increase in an Al-containing phase on the primary particle grain boundaries with a relatively constant and thin $\mathrm{AlF}_{3}$ or aluminium oxyfluoride layer on top. While the presence of a small amount of aluminium in the cathodes is widely believed to enhance the stability of nickel-rich layer oxides, detrimental effects are also expected for an excessive amount of $\mathrm{Al}_{2} \mathrm{O}_{3}$ and the incorporation of $\mathrm{Al}$ in the NMC structure. Our results, therefore, suggest that at some point during the ageing process, the increasing level of Al-containing phases may switch from preventing capacity fading to, perhaps, enhancing it. Given that intergranular films can affect both the mechanical, electrical and chemical properties of polycrystalline systems, determining which effect is predominant under specific conditions will require further study, including the detailed roles of Al contamination in the nickel-rich layered oxides with other reported phenomena such as oxygen depletion, phase transition, and transition metal dissolution.

\section{Experimental Section}

\section{Materials}

The graphite electrodes and polycrystalline NMC811 are fabricated and provided by the Argonne National Laboratory CAMP facility. Briefly, the NMC cathode (batch code A-C020) is composed of 90 wt \% NMC811 (Targray), 5 wt\% carbon black (Timcal C45), 5 wt \% PVDF binder (Solvay 5130), and the graphite electrode consists of 91.83 wt \% graphite powder (Hitachi MagE3), 0.17 wt \% oxalic acid, 6 wt \% PVDF binder (Kureha 9300), and 2 wt \% carbon black (Timcal C45). These laminate electrodes were then punched into $14 \mathrm{~mm}$ (NMC811 cathode) and $15 \mathrm{~mm}$ (graphite electrode) circular disks, respectively. Then, these circular electrodes were dried further at $120^{\circ} \mathrm{C}$ for $12 \mathrm{~h}$ under dynamic vacuum $(\sim 10-$ 2 mbar) in Büchi oven and transferred to glovebox without airexposure. As electrolytes, $1 \mathrm{M} \mathrm{LiPF}_{6}$, EC/EMC 3/7 (LP57, SoulBrain MI, USA) was used in this work, and the separator was Celgard 3501. The Celgard separator was punched into $16 \mathrm{~mm}$ disks, washed in ethanol three times and dried at $50^{\circ} \mathrm{C}$ under vacuum.

The pristine battery material was obtained from a first generation Nissan Leaf battery pack that had undergone QC fail (not because of the material quality but due to the mechanical failure in the contacts) and was never cycled. The end-of-life battery material was obtained from a first generation Nissan Leaf battery pack that was used in a road vehicle for many years. All samples were extracted using a glove box to ensure no atmospheric degradation processes took place.

\section{Battery assembly and cycling}

Long-term cyclability were all performed in NMC/graphite full-cells using 2032 coin cells (Cambridge Energy Solution). Coin-cells were assembled in an Ar-atmosphere $\left(\mathrm{O}_{2}<1 \mathrm{ppm}, \mathrm{H}_{2} \mathrm{O}<1 \mathrm{ppm}\right)$ glovebox. Full cells were composed of a $14 \mathrm{~mm}$ NMC cathode, $16 \mathrm{~mm}$ separator and $15 \mathrm{~mm}$ graphite anode, and $50 \mu \mathrm{L}$ electrolyte was added to each coin cell. The electrolyte used in polycrystalline NMC/graphite full-cells was LP57. The cells were aged at a rate of $\mathrm{C} / 2$ (calculated based on a reversible capacity of $200 \mathrm{mAhg}^{-1}$ of
NMC cathode) between $4.2 \mathrm{~V}$ and $2.5 \mathrm{~V}$ at room temperature ( $20 \pm$ $1{ }^{\circ} \mathrm{C}$ ) using CCCV (constant current constant voltage) charging and CC (constant current) discharging protocol. CCCV charging was composed of a constant current step followed by a constant voltage hold at the upper cut-off voltage, i.e. $4.2 \mathrm{~V}$, until the current dropped below the value of $\mathrm{C} / 20$. Prior to the ageing cycles, one tap charge process and two formation cycles were applied. Tap charge was performed by holding the cells at $1.5 \mathrm{~V}$ for $15 \mathrm{~min}$, followed by a long rest of $6 \mathrm{~h}$ to allow cells to be fully wetted. Formation cycles were conducted at $\mathrm{C} / 20$ rate also using CCCV charging (current limit of the CV step is C/40) and CC discharging protocol. For post-mortem samples at certain voltage or state-of-charge after extended ageing, full-cells were disassembled inside a glovebox.

\section{Material characterisation}

All NMC811 samples were stored and prepared in the Ar glove box. The morphology of NMC811 samples was investigated by a JEOL JSM $7001 \mathrm{~F}$ field emission scanning microscope (FE-SEM) at an acceleration voltage of $15 \mathrm{kV}$ and SEM-FIB (FEI Helios Nanolab 600i). The dark-field scanning transmission electron images (DFSTEM) were taken with an aberration-corrected JEOL JEM-2100 operated at $200 \mathrm{kV}$. With the latter setup, EDX data was obtained by EDAX Octane T Optima windowless $60 \mathrm{~mm}^{2}$ SDD EDX detector with a dwell time of $0.1 \mu$ s. For STEM and EDX analysis, the samples were crushed and placed on lacey-carbon-coated Au grids.

Time-of-Flight Secondary lon Mass Spectrometry (ToF-SIMS), a SIMS 5 spectrometer (IONTOF GmbH, Münster, Germany), was applied for the chemical analysis. The analysis was performed in the high current bunch mode (HCBM) with a $25 \mathrm{keV} \mathrm{Bi}^{+}$primary beam over an area of $250 \mu \mathrm{m} \times 250 \mu \mathrm{m}$ for all NMC samples. For sputtering, a $1 \mathrm{keV} \mathrm{Cs}^{+}$sputtering beam was applied with a raster area of $500 \mu \mathrm{m} \times 500 \mu \mathrm{m}$. The beam current of $\mathrm{Cs}^{+}$was consistent during sputtering for all three samples. Additionally, all the samples were mounted in an Ar-filled glovebox and were transferred into the instrument within a vacuum suitcase which was opened in the loadlock chamber until the pressure was lower than $10^{-5} \mathrm{mbar}$ in order to avoid the influence from ambient environment.

\section{Acknowledgements}

We would like to thank Mathew Bilton and Adam Papworth for assistance with FIB/STEM experiments. This work was supported by the Faraday Institution through awards FIRG001 "Degradation" and FIRG005 "ReLiB".

\section{Conflict of Interest}

The authors declare no conflict of interest.

Keywords: aluminium coating • Li-ion batteries · layered oxides $\cdot \mathrm{NMC} 811 \cdot$ Ni-rich cathodes

[1] J. W. Choi, D. Aurbach, Nat. Rev. Mater. 2016, 1, 1-16.

[2] P. K. Nayak, L. Yang, W. Brehm, P. Adelhelm, Angew. Chem. Int. Ed. 2018, 57, 102-120; Angew. Chem. 2018, 130, 106-126. 
[3] G. Zubi, R. Dufo-López, M. Carvalho, G. Pasaoglu, Renewable Sustainable Energy Rev. 2018, 89, 292-308.

[4] J. M. Tarascon, M. Armand, Nature 2001, 414, 359-367.

[5] T. Kim, W. Song, D.-Y. Son, L. K. Ono, Y. Qi, J. Mater. Chem. A 2019, 7, 2942-2964.

[6] G. E. Blomgren, J. Electrochem. Soc. 2016, 164, A5019-A5025.

[7] V. Etacheri, R. Marom, R. Elazari, G. Salitra, D. Aurbach, Energy Environ. Sci. 2011, 4, 3243-3262.

[8] J. Kim, H. Lee, H. Cha, M. Yoon, M. Park, J. Cho, Adv. Energy Mater. 2018, 8, 1702028.

[9] W. Liu, P. Oh, X. Liu, M.-J. Lee, W. Cho, S. Chae, Y. Kim, J. Cho, Angew. Chem. Int. Ed. 2015, 54, 4440-4457; Angew. Chem. 2015, 127, 45184536.

[10] D. Wang, W. Liu, X. Zhang, Y. Huang, M. Xu, W. Xiao, Int. J. Photoenergy 2019, 2019, 2730849.

[11] A. Wang, S. Kadam, H. Li, S. Shi, Y. Qi, npj Comput. Mater. 2018, 4, 15.

[12] Z. Xu, M. M. Rahman, L. Mu, Y. Liu, F. Lin, J. Mater. Chem. A 2018, 6, 21859-21884

[13] H. Zhang, B. M. May, J. Serrano-Sevillano, M. Casas-Cabanas, J. Cabana, C. Wang, G. Zhou, Chem. Mater. 2018, 30, 692-699.

[14] F. Lin, I. M. Markus, D. Nordlund, T.-C. Weng, M. D. Asta, H. L. Xin, M. M. Doeff, Nat. Commun. 2014, 5, 3529.

[15] P. Yan, J. Zheng, M. Gu, J. Xiao, J.-G. Zhang, C.-M. Wang, Nat. Commun. 2017, 8, 14101.

[16] Y. Makimura, T. Sasaki, T. Nonaka, Y. F. Nishimura, T. Uyama, C. Okuda, Y. Itou, Y. Takeuchi, J. Mater. Chem. A 2016, 4, 8350-8358.

[17] M.-T. F. Rodrigues, C. Liao, K. Kalaga, I. A. Shkrob, D. P. Abraham, ACS Appl. Mater. Interfaces 2019, 2, 5380-5385.

[18] M. Bettge, Y. Li, B. Sankaran, N. D. Rago, T. Spila, R. T. Haasch, I. Petrov, D. P. Abraham, J. Power Sources 2013, 233, 346-357.

[19] M. Xu, Z. Chen, L. Li, H. Zhu, Q. Zhao, L. Xu, N. Peng, L. Gong, J. Power Sources 2015, 281, 444-454.

[20] B. Han, B. Key, S. H. Lapidus, J. C. Garcia, H. Iddir, J. T. Vaughey, F. Dogan, ACS Appl. Mater. Interfaces 2017, 9, 41291-41302.

[21] S.-T. Myung, K. Izumi, S. Komaba, Y.-K. Sun, H. Yashiro, N. Kumagai, Chem. Mater. 2005, 17, 3695-3704.

[22] S. S. Zhang, T. R. Jow, J. Power Sources 2002, 109, 458-464.

[23] X. Zhang, B. Winget, M. Doeff, J. W. Evans, T. M. Devine, J. Electrochem. Soc. 2005, 152, B448-B454.

[24] S.-T. Myung, Y. Sasaki, S. Sakurada, Y.-K. Sun, H. Yashiro, Electrochim. Acta 2009, 55, 288-297.

[25] T. Ma, G.-L. Xu, Y. Li, L. Wang, X. He, J. Zheng, J. Liu, M. H. Engelhard, P. Zapol, L. A. Curtiss, J. Jorne, K. Amine, Z. Chen, J. Phys. Chem. Lett. 2017, 8, 1072-1077.

[26] S.-T. Myung, Y. Hitoshi, Y.-K. Sun, J. Mater. Chem. 2011, 21, 9891-9911.

[27] A. Heckmann, M. Krott, B. Streipert, S. Uhlenbruck, M. Winter, T. Placke, ChemPhysChem 2017, 18, 156-163.
[28] T. C. Hyams, J. Go, T. M. Devine, J. Electrochem. Soc. 2007, 154, C390C396.

[29] X. Zhang, T. M. Devine, J. Electrochem. Soc. 2006, 153, B375.

[30] E. Krämer, T. Schedlbauer, B. Hoffmann, L. Terborg, S. Nowak, H. J. Gores, S. Passerini, M. Winter, J. Electrochem. Soc. 2012, 160, A356-A360.

[31] B. L. Mehdi, A. Stevens, J. Qian, C. Park, W. Xu, W. A. Henderson, J. G. Zhang, K. T. Mueller, N. D. Browning, Sci. Rep. 2016, 6, 34267.

[32] P.-C. Tsai, B. Wen, M. Wolfman, M.-J. Choe, M. S. Pan, L. Su, K. Thornton J. Cabana, Y.-M. Chiang, Energy Environ. Sci. 2018, 11, 860-871.

[33] C. Xu, K. Marker, J. Lee, A. Mahadevegowda, P. J. Reeves, S. J. Day, M. F. Groh, S. P. Emge, C. Ducati, B. Layla Mehdi, C. C. Tang, C. P. Grey, Nat Mater. 2021, 20, 84-92.

[34] Y.-C. Li, W. Xiang, Z.-G. Wu, C.-L. Xu, Y.-D. Xu, Y. Xiao, Z.-G. Yang, C.-J. Wu, G.-P. Lv, X.-D. Guo, Electrochim. Acta 2018, 291, 84-94.

[35] L. Zou, J. Li, Z. Liu, G. Wang, A. Manthiram, C. Wang, Nat. Commun. 2019, 10, 3447

[36] S. S. Kanyal, D. S. Jensen, Z. Zhu, M. R. Linford, Surf. Sci. Spectra 2015 22, 7-13.

[37] L. M. Thompson, W. Stone, A. Eldesoky, N. K. Smith, C. R. M. McFarlane, J. S. Kim, M. B. Johnson, R. Petibon, J. R. Dahn, J. Electrochem. Soc. 2018 165, A2732-A2740.

[38] J. A. Gilbert, I. A. Shkrob, D. P. Abraham, J. Electrochem. Soc. 2017, 164, A389-A399.

[39] W. Li, A. Dolocan, P. Oh, H. Celio, S. Park, J. Cho, A. Manthiram, Nat. Commun. 2017, 8, 14589.

[40] Y. Qian, P. Niehoff, M. Börner, M. Grützke, X. Mönnighoff, P. Behrends, S. Nowak, M. Winter, F. M. Schappacher, J. Power Sources 2016, 329, 31-

[41] S. Fang, D. Jackson, M. L. Dreibelbis, T. F. Kuech, R. J. Hamers, J. Power Sources 2018, 373, 184-192.

[42] J. Li, A. Manthiram, Adv. Energy Mater. 2019, 9, 1902731.

[43] S. Pennycook, Ultramicroscopy 1989, 30, 58-69.

[44] P. Xiao, T. Shi, W. Huang, G. Ceder, ACS Energy Lett. 2019, 4, 811-818.

[45] R. J. Clément, Z. Lun, G. Ceder, Energy Environ. Sci. 2020, 13, 345-373.

[46] C. Tian, F. Lin, M. M. Doeff, Acc. Chem. Res. 2018, 51, 89-96.

[47] K. Araki, N. Taguchi, H. Sakaebe, K. Tatsumi, Z. Ogumi, J. Power Sources 2014, 269, 236-243.

[48] W. Zhu, X. Huang, T. Liu, Z. Xie, Y. Wang, K. Tian, L. Bu, H. Wang, L. Gao, J. Zhao, Coating 2019, 9, 92

[49] H. D. Espinosa, P. D. Zavattieri, Mech. Mater. 2003, 35, 333-364.

[50] J. Luo, Crit. Rev. Solid State Mater. Sci. 2007, 32, 67-109.

Manuscript received: May 18, 2021

Accepted manuscript online: June 13, 2021

Version of record online: 


\section{COMMUNICATIONS}

The role of Al: We report that the level of aluminium contamination on nickel-rich manganese cobalt oxide increases as a function of battery cycles; in particular, the Al-containing phases were observed at surfaces and grain boundaries. This observation of increased Al content can bring new insights into the ongoing discussions concerning the capacity fading phenomenon of nickel-rich layered oxide materials in lithium-ion batteries.

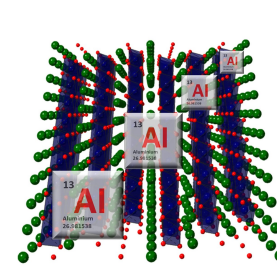

Aluminium contamination

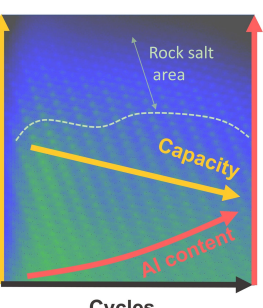

Cycles
Dr. J. Lee, Dr. H. Amari, Dr. M. Bahri, Dr. Z. Shen, Dr. C. Xu, Dr. Z. Ruff, Prof. C. P. Grey, Dr. O. Ersen, Dr. A. Aguadero, Prof. N. D. Browning, Dr. B. L. Mehdi*

$1-9$

The Complex Role of Aluminium Contamination in Nickel-Rich Layered Oxide Cathodes for Lithium-Ion Batteries 